\title{
IDENTIFICAÇÃO DE MARCADOR RAPD E SCAR RELACIONADOS AO CARACTERE FLORESCIMENTO PRECOCE EM Eucalyptus grandis ${ }^{1}$
}

\author{
IDENTIFICATION OF RAPD AND SCAR MARKER RELATED TO EARLY FLOWERING IN \\ Eucalyptus grandis
}

\author{
Douglas Silva Domingues $^{2}$ Ana Paula Cazerta Farro ${ }^{3}$ Virgínia Elias Coscrato ${ }^{4}$ \\ Eduardo José de Mello ${ }^{5}$ Shinitiro Oda ${ }^{5}$ Celso Luís Marino ${ }^{6}$

\section{RESUMO}

No melhoramento genético de eucalipto, existem ainda poucos instrumentos disponíveis para acelerar a seleção de genótipos superiores, e uma das principais estratégias sugeridas para se acelerar este processo é a identificação de marcadores moleculares ligados a caracteres de interesse. Foram avaliados 81 marcadores RAPD em uma progênie $\mathrm{F}_{1}$ de Eucalyptus grandis $\mathrm{W}$. Hill ex Maiden segregante para o caractere florescimento precoce utilizando-se a técnica de Bulked Segregant Analysis (BSA). Dentre esses marcadores, um se mostrou relacionado ao caractere, sendo então convertido em Sequence Characterized Amplified Region (SCAR), avaliado em cada indivíduo da progênie e validado em outras progênies que apresentam o caractere. O SCAR mostrou-se informativo na progênie que apresenta um dos parentais como doador do fragmento polimórfico, com eficiência de $60 \%$. Esses resultados descrevem o primeiro marcador SCAR desenvolvido para eucalipto e confirmam a utilidade da técnica de BSA como ferramenta molecular no melhoramento genético florestal e que poderia ser empregada para localização de marcadores ligados a diferentes caracteres silviculturais.

Palavras-chave: Bulked Segregant Analysis (BSA); Eucalyptus; florescimento precoce; Sequence Characterized Amplified Region (SCAR).

\section{ABSTRACT}

There are few available tools in eucalyptus breeding to accelerate the selection of superior genotypes, and one of the main tools to improve this process is the use of molecular markers linked to traits of interest. Using "Bulked Segregant Analysis", we evaluated 81 RAPD molecular markers in a Eucalyptus grandis W. Hill ex Maiden progeny that segregates for early flowering, and one marker was identified as related to this trait. This RAPD marker was converted into a Sequence-Characterized Amplified Region (SCAR), which was then evaluated in a $\mathrm{F}_{1}$ progeny, and validated in other progenies that presents this trait. The SCAR marker was informative in the progeny in which one of the parental was the donor of the band, with an efficiency of $60 \%$. These results describe the first SCAR marker developed for eucalypt and confirm this technique as a useful molecular tool for forestry breeding which could be employed to locate markers linked to other silvicultural traits.

Keywords: Bulked Segregant Analysis (BSA); early flowering, Eucalyptus, Sequence Characterized Amplified Region (SCAR).

1. Trabalho de conclusão de curso (Ciências Biológicas - Bacharelado) apresentado ao Departamento de Genética, Instituto de Biociências, Universidade Estadual Paulista (UNESP).

2. Biólogo, Instituto de Biociências, Universidade Estadual Paulista, Campus de Botucatu, Distrito de Rubião Júnior, s/n., CEP 18618-000, Botucatu (SP). Bolsista de Iniciação Científica da FAPESP. dougsd@ig.com.br

3. Bióloga, Doutoranda do Programa de Pós Graduação em Ciências Biológicas (Genética), Instituto de Biociências, Universidade Estadual Paulista, Campus de Botucatu, Distrito de Rubião Júnior, s/n., CEP 18618-000, Botucatu (SP). anafarro@ibb.unesp.br

4. Biomédica, Doutoranda do Programa de Pós Graduação em Ciências Biológicas (Genética), Instituto de Biociências, Universidade Estadual Paulista, Campus de Botucatu, Distrito de Rubião Júnior, s/n., CEP 18618-000, Botucatu (SP). vecoscrato@ibb.unesp.br

5. Engenheiro Florestal, Técnico da Empresa Suzano Papel e Celulose SA, Av. Dr. José Lembo, 1010, CEP 18207780, Itapetininga (SP).emello@suzano.com.br/soda@suzano.com.br

6. Biólogo, Dr., Professor Assistente do Departamento de Genética, Instituto de Biociências, Universidade Estadual Paulista, Campus de Botucatu, Distrito de Rubião Júnior, s/n., CEP 18618-000, Botucatu (SP). clmarino@ibb.unesp.br

Recebido para publicação em 10/09/2004 e aceito em 16/08/2006. 


\section{INTRODUÇÃO}

O gênero florestal Eucalyptus é originário da Austrália e teve algumas de suas espécies introduzidas no Brasil entre o final do século XIX e início do século XX.

O eucalipto é utilizado no País como fonte de madeira e matéria-prima para a produção de celulose e papel. O Brasil ocupa atualmente uma posição de destaque na produção mundial desses materiais.

Quando comparado a outros países, os programas das empresas brasileiras para o melhoramento genético de eucalipto encontram-se em fase bastante adiantada. Técnicas moleculares já são utilizadas para a avaliação da variabilidade genética de populações (Leite et al., 2002; Mezzena, 2003), elaboração de mapas genéticos (Verhagen et al., 1996; Brondani et al., 1998, 2002) e mapeamento genético de caracteres quantitativos de interesse na produção (Grattapaglia et al., 1994, 1995, 1996; Junghans et al., 2003).

Existe um grande interesse por parte dos profissionais da área de silvicultura de se utilizar o melhoramento assistido por marcadores (Marker Assisted Selection - MAS) para o caractere de tempo de florescimento, já que o longo período de florescimento dificulta os estudos genéticos dessa caraterística em gêneros como Eucalyptus (Southerton et al.,1998).

Os estudos realizados em espécies-modelo indicam que o florescimento está ligado à expressão de genes de identidade do meristema floral, como o AGAMOUS (Yanofsky et al., 1990), APETALAl (Pena et al., 2001), TFL1 (Araki et al., 1999) e LEAFY (Weigel et al., 1992). Foi constatado que Eucalyptus globulus Labill. possui um homólogo ao gene APETALA1 (Kyozuka et al., 1997) e LEAFY (Southerton et al., 1998) assim como dois homólogos do gene $A G A M O U S$ já foram mapeados em uma progênie $\mathrm{F}_{1}$ desta espécie (Thamarus et al., 2002). Recentemente, também foi clonado em Eucalyptus grandis um homólogo ao gene LEAFY (Dornelas et al., 2002). Embora o florescimento seja um caractere dependente da ação de vários genes (Levy e Dean, 1998 a, b) e por isso, muitas vezes considerado um caractere quantitativo (QTL Quantitative Trait Loci), o presente trabalho partiu da hipótese de que poderia ser identificado um marcador molecular relacionado ao gene de efeito principal no florescimento precoce da progênie em estudo, como o que é proposto por Or et al. (1999) e Missiaggia et al. (2002).

Embora a capacidade de florescimento precoce em eucalipto já tenha sido relatada na literatura, (Moncur et al., 1994 apud Junghans, 2000) e Missiaggia et al. (2002) tenham mapeado marcadores microssatélites relacionados ao caractere florescimento precoce em híbridos de eucalipto (Eucalyptus urophylla $\mathrm{S}$. T. Blake X Eucalyptus grandis W. Hill ex Maiden), os programas de melhoramento genético até o momento são pouco atuantes na seleção desse caractere.

O florescimento precoce pode ser útil na introdução de alelos de interesse em uma população de melhoramento genético, reduzindo o longo tempo necessário para uma geração de melhoramento (Grattapaglia et al., 1996; Missiaggia et al., 2002). Genótipos de florescimento precoce também são de interesse na produção de mel de alta qualidade de florestas de eucalipto (Rocha et al., 2005). Contudo, este caractere é indesejável nas plantações comerciais de eucalipto para produção de celulose, já que árvores que entram rapidamente em fase reprodutiva podem não alcançar seu desenvolvimento máximo na fase vegetativa, resultando em uma menor produtividade. Portanto, marcadores moleculares que identifiquem árvores que florescem precocemente ainda no estágio de muda seriam de grande valia para o melhoramento florestal do gênero.

Uma estratégia utilizada para a identificação de marcadores moleculares relacionados a caracteres de interesse é a utilização de marcadores RAPD (Random Amplified Polymorphic DNA), combinada com a estratégia de "Bulked Segregant Analysis" (BSA - Michelmore et al., 1991). Com essas técnicas, foram identificados diversos marcadores moleculares ligados a caracteres de interesse para diversas espécies vegetais (Moretzsohn et al., 2000; Avila et al., 2003; Junghans et al., 2003). Em eucalipto, a BSA foi empregada na identificação de marcadores relacionados ao teor de cera em folhas de Eucalyptus gunnii Hook. F. (Wirthensohn et al., 1999) e à resistência à ferrugem em Eucalyptus grandis (Junghans et al., 2003).

Em espécies alógamas, como as do gênero Eucalyptus sp., altos níveis de heterozigose são encontrados na maioria dos locos, o que permite a utilização da BSA sem a necessidade de retrocruzamentos partindo da estratégia de "pseudo-testcross", a qual infere uma segregação de 1:1 do marcador RAPD na 
geração $\mathrm{F}_{1}$, resultado do cruzamento de um parental heterozigoto para aquele marcador com outro que não apresenta a marca (Grattapaglia et al., 1994, 1995).

Para facilitar a repetibilidade de resultados obtidos por RAPD e melhor avaliar a segregação de um marcador relacionado ao caractere de interesse, uma opção é o desenvolvimento de um marcador específico para a região genômica em estudo, o Sequence Characterized Amplified Region (SCAR). O desenvolvimento de SCARs (Paran e Michelmore, 1993) pode ser utilizado na seleção assistida para resistência a doenças, mapeamento de genes de interesse e identificação de cultivares, entre outras finalidades (Nietsche et al., 2000; Martins Filho et al., 2002; Rameau et al., 1998; Tar'an et al., 2003).

O objetivo do presente trabalho foi obter um marcador de DNA relacionado ao florescimento precoce em uma progênie segregante de eucalipto, utilizando a técnica de BSA e marcadores RAPD. O marcador encontrado foi convertido em SCAR, avaliado nessa progênie e validado em outras progênies que possuem o caractere.

\section{MATERIAL E MÉTODO}

\section{Material vegetal}

Para a identificação de marcadores relacionados ao florescimento precoce, foi utilizada uma progênie $\mathrm{F}_{1}$ de Eucalyptus grandis de 115 indivíduos, plantados no município de Itapetininga-SP, resultantes do cruzamento controlado entre um parental que apresentava florescimento precoce (antes de dois anos - P1) e outro de florescimento normal (florescimento depois dos dois anos - P2). Essas árvores-elite são utilizadas para produção de progênies utilizadas em diversos plantios comerciais da Suzano Bahia Sul Papel e Celulose SA.

\section{Avaliação do caractere e da herança mendeliana}

Após dois anos de crescimento da progênie, observou-se que a relação entre o número de árvores que já haviam florescido, que apresentavam florescimento precoce, e árvores que ainda não haviam florescido aproximava-se de 1:1, sugerindo uma segregação mendeliana do caractere. Dessa forma, foi levantada a hipótese de "pseudo-testcross" (Grattapaglia et al., 1994, 1995), considerando que o parental de florescimento precoce seria heterozigoto para o gene responsável pelo caractere e o parental de florescimento normal seria homozigoto recessivo. Assim, um teste de qui-quadrado foi utilizado para testar a hipótese de segregação 1:1 na progênie estudada. O teste de qui-quadrado foi realizado na ferramenta online desenvolvida por Preacher (2001) e disponível na página da internet http://www.unc.edu/ preacher/chisq/chisq.htm, do endereço eletrônico http://www.quantpsy.org/.

\section{Extração de DNA}

Folhas jovens de todos os indivíduos foram coletadas e armazenadas a $-20^{\circ} \mathrm{C}$ até a extração de DNA. O DNA genômico foi extraído de acordo com o protocolo sugerido por Ferreira e Grattapaglia (1998) e quantificado por comparação a um padrão de peso conhecido, partindo de eletroforese em gel de agarose 0,8\% com tampão Tris-Borato-EDTA (TBE) $1 \mathrm{X}$, corados com brometo de etídio. Para padronização das reações de amplificação, o DNA extraído de cada amostra foi diluído para uma concentração de $5 \mathrm{ng} / \mu \mathrm{L}$.

\section{Bulked Segregant Analysis e Análise RAPD}

Para a análise por BSA, foram selecionados aleatoriamente dez indivíduos que floresceram precocemente $(\mathrm{F})$ e dez que floresceram em período normal $(\mathrm{N})$. Quantidades equimolares de DNA desses indivíduos foram utilizadas para a preparação de dois "bulks" - BF e BN. Foram avaliados 81 primers RAPD, dos kits AD, G, H, J, P, W, X e Y da Operon Tecnologies, Inc. O marcador polimórfico entre os "bulks" foi testado em todos os indivíduos da progênie, e depois de confirmado o polimorfismo, esse marcador foi convertido em SCAR.

A reação de amplificação RAPD tinha volume final de $13 \mu \mathrm{L}$, com uma quantidade de $15 \mathrm{ng}$ de DNA, $1,30 \mu \mathrm{L}$ de PCR Buffer 10X, $1 \mathrm{mM}$ de $\mathrm{MgCl}_{2}, 1,04 \mu \mathrm{L}$ de BSA a $10 \mathrm{mg} / \mathrm{mL}$ (Bovine Serine Albumin Invitrogen), $0,25 \mathrm{mM}$ de cada dNTP, $0,3 \mu \mathrm{M}$ de "primer" e $1 \mathrm{U}$ de Taq DNA Polimerase (Invitrogen Brasil). As reações eram cobertas com óleo mineral para evitar evaporação e levadas a um termociclador PTC-100 (MJ Research). O programa de amplificação consistia de uma desnaturação inicial de $3 \mathrm{~min}$ a $94^{\circ} \mathrm{C}$, e 41 ciclos de $1 \min$ a $92^{\circ} \mathrm{C} ; 1 \min$ a $35^{\circ} \mathrm{C}$ e $2 \min$ a $72^{\circ} \mathrm{C}$. As amostras foram submetidas a uma extensão final de 
5 min a $72^{\circ} \mathrm{C}$ e mantidas a $4^{\circ} \mathrm{C}$ até sua retirada do termociclador.

Os fragmentos da amplificação foram separados por eletroforese em gel de agarose $1,5 \%$, usando como tampão TBE $1 \mathrm{X}$, corado com brometo de etídio. A visualização do gel foi realizada sobre um transiluminador de luz U.V., no sistema de fotodocumentação digital Eagle Eye II (Stratagene).

\section{Desenvolvimento do marcador SCAR}

A banda RAPD considerada relacionada ao florescimento precoce foi recortada do gel e purificada com o kit Concert ${ }^{\mathrm{TM}}$ Rapid Gel Extraction System (Gibco BRL - Life Tecnologies). O produto purificado foi reamplificado com o mesmo "primer" RAPD nas mesmas condições mencionadas anteriormente, com exceção da extensão final, que foi de $30 \mathrm{~min}$ a $72^{\circ} \mathrm{C}$. O fragmento reamplificado foi submetido à nova corrida de eletroforese gel de agarose 1,5\%, extração do gel e purificação.

O fragmento foi clonado no vetor pGEM-T Easy Vector System I (Promega) e inserido em células competentes UltraMax ${ }^{\mathrm{TM}} \mathrm{DH} 5 \alpha-\mathrm{FT}^{\mathrm{TM}}$ (Life Tecnologies, GibcoBRL), seguindo as orientações do protocolo dos fornecedores. O DNA das colônias brancas foi seqüenciado parcialmente (na posição "forward" e "reverse") utilizando nucleotídeos marcados com fluorescência e primers universais M13 em um seqüenciador ABI 3100 Genetic Analyzer (Applied Biosystems). As seqüências-consenso correspondentes às extremidades do fragmento foram utilizadas para o desenho de dois "primers" (denominados SEEF - SCAR for Eucalyptus Early Flowering) de 24 bases cada, das quais dez correspondem à seqüência original do "primer" RAPD, seguido de 14 bases internas das extremidades do fragmento de interesse.

\section{Amplificação e análise do marcador SCAR}

A reação SCAR foi composta de 10ng de DNA, 1,30 $\mu \mathrm{L}$ PCR Buffer 10X, 1mM de $\mathrm{MgCl}_{2}, 1,04 \mu \mathrm{L}$ de BSA a $10 \mathrm{mg} / \mathrm{ml}, 0,25 \mathrm{mM}$ de cada dNTP, $1 \mathrm{U}$ de Taq DNA Polimerase e $0,2 \mu \mathrm{M}$ dos "primers" SEEF 1 e 2. O programa de amplificação consistiu de desnaturação inicial de 3 min a $96^{\circ} \mathrm{C}$ e 35 ciclos de 1 min a $94^{\circ} \mathrm{C} ; 1$ $\min$ a $65^{\circ} \mathrm{C}$ e 2 min a $72^{\circ} \mathrm{C}$. As amostras foram submetidas a uma extensão final de 5 min a $72^{\circ} \mathrm{C}$ e mantidas a $4^{\circ} \mathrm{C}$ até sua retirada do termociclador. Os produtos da reação foram amplificados em gel de agarose $1 \%$, feitos com tampão TBE $1 \mathrm{X}$ e corado com brometo de etídio.

Os "primers" foram testados nos parentais da progênie para confirmação da amplificação do fragmento de interesse e posteriormente avaliados nos indivíduos da progênie $F_{1}$.

\section{Validação do marcador SCAR}

Para validação do marcador, os "primers" SEEF 1 e 2 foram avaliados em vinte indivíduos de florescimento precoce (antes dos 2 anos), provenientes de outros cruzamentos da Companhia Suzano de Papel e Celulose. Dez indivíduos eram do cruzamento entre P1 e um clone geneticamente não-relacionado com a progênie $F_{1}$ e dez indivíduos eram resultantes do cruzamento entre o clone $\mathrm{P} 2$ e outro não-relacionado geneticamente com os indivíduos da progênie inicial.

\section{Eficiência dos "primers" SEEF no diagnóstico do caractere}

A eficiência do marcador foi determinada pela porcentagem de indivíduos da progênie $F_{1}$ que possuíam fenótipo correspondente à amplificação do SCAR. Os indivíduos da progênie foram considerados recombinantes quando possuíam florescimento precoce e não amplificaram o marcador SCAR, ou vice-versa.

\section{RESULTADOS E DISCUSSÃO}

\section{Avaliação da segregação mendeliana do caractere}

A hipótese de segregação mendeliana 1:1 do caractere florescimento precoce com base na avaliação de indivíduos que floresceram até 2 anos de idade, em um cruzamento do tipo "pseudo-testcross" foi confirmada pela análise de qui-quadrado, com valor de $p$ de 0,40132661 (Tabela 1), evidenciando que a progênie é adequada para a triagem de marcadores moleculares relacionados ao florescimento precoce. Junghans et al. (2003), analisando marcadores moleculares RAPD relacionados à resistência à ferrugem em Eucalyptus sp., utilizaram estratégia semelhante para avaliação da segregação mendeliana na progênie utilizada em seu trabalho. 
TABELA 1: Segregação do caractere florescimento precoce na progênie estudada. Foram considerados indivíduos de florescimento precoce aqueles que floresceram antes dos dois anos de idade e de florescimento normal os que não haviam ainda florescido.

TABLE 1: Early flowering segregation in the studied progeny. It was considered individuals of early flowering the ones that flowered before 2 years old, and normal flowering the ones that had not flowered yet.

\begin{tabular}{l|c|c|c|c}
\hline Fenótipo & Número de indivíduos & Segregação esperada & $\chi^{2}$ & Valor de $p$ \\
\hline Florescimento precoce & 62 & $1: 1$ & 0,704 & 0,40132661 \\
Florescimento normal & 53 & - & - & - \\
\hline
\end{tabular}

\section{Análise de BSA e identificação de marcador RAPD}

Entre os 81 "primers" avaliados, apenas o primer OPG-16 (seqüência AGCGTCCTCC) apresentou uma banda polimórfica entre os dois "bulks" de DNA, na região de 1.400 pares de base (pb) (Figura 1). Nos parentais, o fragmento polimórfico está presente naquele que floresce em tempo normal (P2).

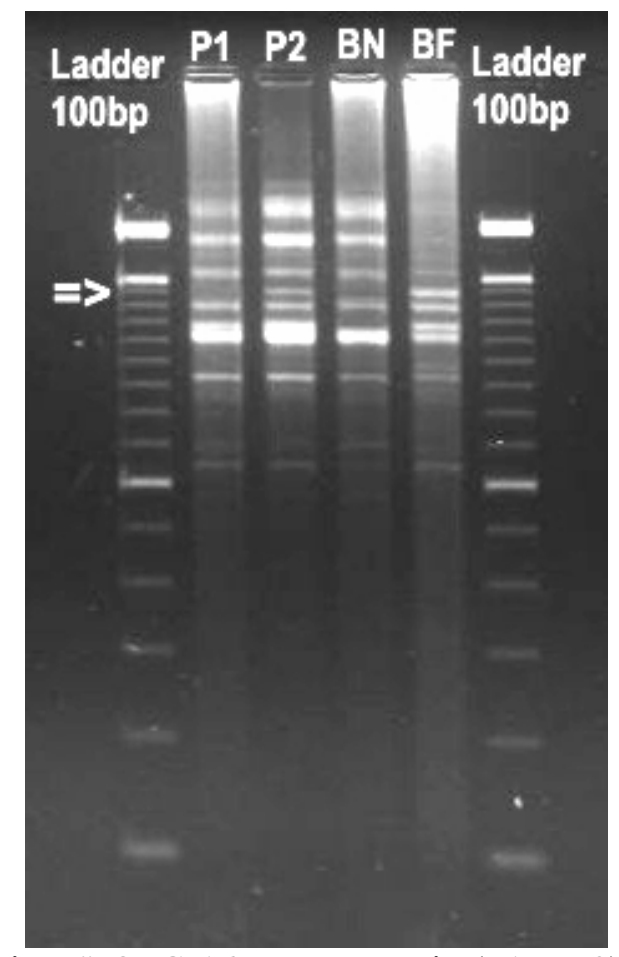

FIGURA 1: Amplificação do "primer" OPG-16 nos parentais (P1 e P2) e nos "bulks" (BF e BN). A seta indica a banda polimórfica. Na primeira e na última coluna, encontra-se um padrão conhecido de DNA (Ladder 100bp).

FIGURE 1: OPG-16 primer amplification in the parents (P1 and $\mathrm{P} 2)$ and bulks (BF and $\mathrm{BN})$. The arrow shows the polymorphic band. A DNA size marker is located in the first and in last columns (100-bp Ladder).

$\mathrm{Na}$ avaliação individual do "primer" OPG-16 nos "bulks" (Figura 2), foi verificado que o fragmento G16 1400 segrega em conjunto com o caractere florescimento precoce em 18 dos vinte indivíduos, o que indicou que esse marcador poderia estar próximo ao loco que controla esse caractere na progênie, por isso, $o$ marcador foi convertido em SCAR. 


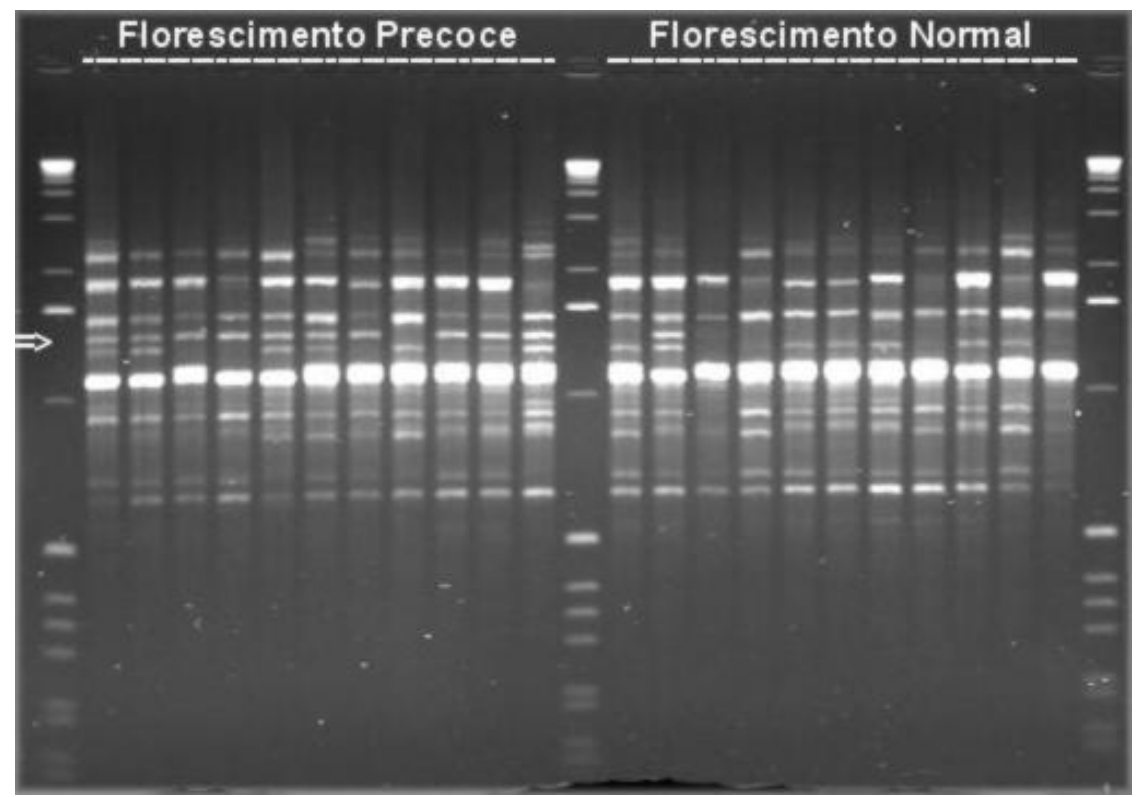

FIGURA 2: Amplificação do primer OPG-16 em cada indivíduo dos "bulks". A seta indica a banda polimórfica relacionada ao florescimento precoce. Na primeira e na última coluna, encontra-se um padrão conhecido de DNA (Ladder $1 \mathrm{~Kb}$ ).

FIGURE 2: OPG-16 primer amplification in each tree of the bulks. The arrow shows the polymorphic band related to early flowering. A DNA size marker is located in the first and in last columns $(1 \mathrm{~kb}$ Ladder).

\section{Desenvolvimento e avaliação do marcador SCAR}

O fragmento $\mathrm{G}_{16} 6_{1400}$ foi clonado e parcialmente seqüenciado. Partindo do seqüenciamento, foram desenhados os dois "primers" SCAR: SEEF 1 (seqüência: AGCGTCCTCCCTCCCGACTGAAAC) e SEEF 2 (seqüência: AGCGTCCTCCTAGGGCTTACGATG), os quais foram testados nos parentais da progênie $\mathrm{F}_{1}$. Verificou-se que o fragmento amplificado é do mesmo tamanho que o encontrado na análise RAPD e está presente no parental de florescimento normal (Figura 3).

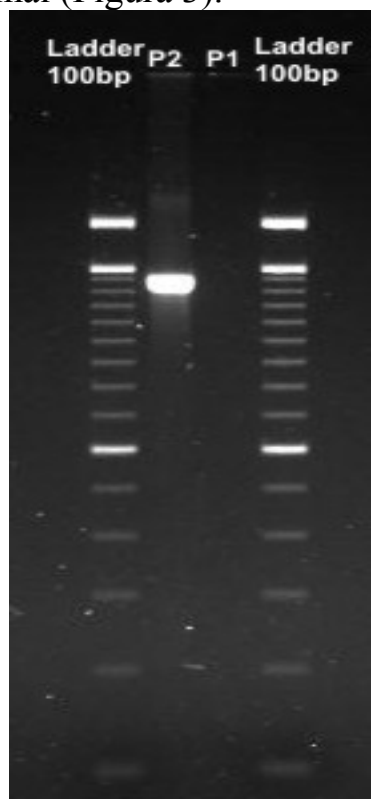

FIGURA 3: Fragmento RAPD G16 $6_{1400}$ convertido em marcador SCAR. Na primeira e na última coluna, encontra-se um padrão conhecido de DNA (Ladder 100bp).

FIGURE 3: G16 ${ }_{1400}$ RAPD fragment converted into SCAR marker. A DNA size marker is located in the first and in last columns (100-bp Ladder). 
O fato do fragmento relacionado ao florescimento precoce aparecer no parental que não possui esse caractere, pode significar que esse marcador flanqueia o alelo recessivo presente nesse indivíduo (já que ele seria heterozigoto). Isso também explicaria o aparecimento de indivíduos recombinantes, uma vez que o marcador amplifica uma região genômica que flanqueia o loco ligado ao caractere, como esquematizado na Figura 4.

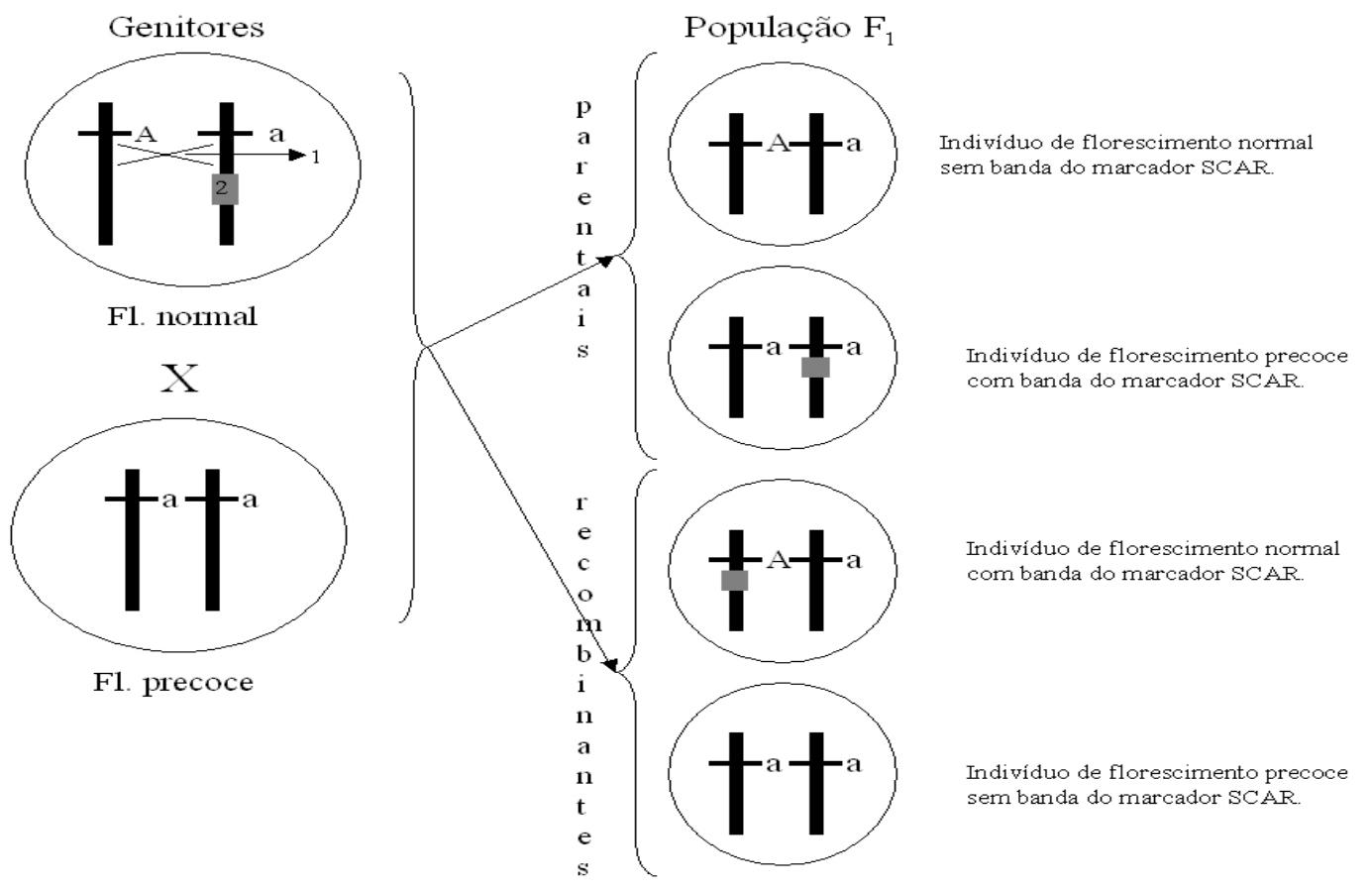

FIGURA 4: Perfil de genótipos, fenótipos e distribuição do marcador SCAR na progênie estudada. Legenda: 1) evento de recombinação na região genômica entre o principal loco relacionado ao florescimento precoce e a região amplificada pelo marcador SCAR; 2) região genômica amplificada pelos "primers" SEEF (caixa cinza indicada na progênie F1).

FIGURE 4: Profile for genotypes, phenotypes, and distribution of the SCAR marker in the studied progeny. Legend: 1) recombination event in the genomic region between the major locus related to early flowering and the region amplified by the SCAR marker; 2) genomic region amplified by the SEEF primers (grey box indicated in the F1 progeny).

O conjunto de "primers" SEEF foi avaliado nos 115 indivíduos da progênie $F_{1}$. Sessenta e nove indivíduos da progênie tiveram a segregação da banda correspondente com seu fenótipo e 46 indivíduos foram "recombinantes", ou seja, tinham florescimento normal e amplificaram o marcador SCAR, ou viceversa (Tabela 2). Portanto, os "primers" SEEF 1 e 2 diagnosticaram o florescimento precoce na progênie com $60 \%$ de eficiência.

TABELA 2: Lista de indivíduos avaliados e correlação entre seus fenótipos e o fragmento amplificado pelos "primers" SEEF.

TABLE 2: List of evaluated trees and correlation between their phenotype and the marker amplified by SEEF primers.

\begin{tabular}{l|c|c|c}
\hline Fenótipo & N. indivíduos avaliados & Fenótipo correspondente com a banda & Recombinantes \\
\hline Florescimento precoce & 62 & 41 & 21 \\
Florescimento normal & 53 & 28 & 25 \\
\hline Total & 115 & 69 & 46 \\
\hline
\end{tabular}

Uma vez que este é um marcador baseado em DNA, apresenta a vantagem que variâncias ambientais não atuam em seu índice de eficiência. Por isso, a recombinação observada na progênie estudada e que influi na eficiência do marcador está ligada à distância física entre a região amplificada pelos "primers" SEEF e o loco controlador do florescimento precoce, que distorce a co-segregação entre o marcador identificado e o caractere em estudo. 


\section{Validação do marcador identificado para seleção assistida}

Para validação, o marcador identificado foi avaliado em vinte indivíduos meio-irmãos da progênie $F_{1}$ em estudo que apresentavam florescimento precoce. Dentre os dez indivíduos provenientes do cruzamento entre P2 e um clone geneticamente não-relacionado com a progênie $F_{1}$, seis amplificaram o fragmento de $1400 \mathrm{pb}$ relacionado ao florescimento precoce. Nos dez indivíduos resultantes do cruzamento entre o clone P1 e outro não-relacionado geneticamente com os indivíduos da progênie inicial, nenhum amplificou o fragmento em questão.

Esses dados com índice de recombinação semelhante ao obtido na progênie $F_{1}$ confirmam a possibilidade de transferência do marcador para outras populações em que um dos parentais seja o clone P2.

Apesar do marcador SCAR desenvolvido ser transferível para outros cruzamentos, ele apresenta um índice de recombinação na progênie $\mathrm{F}_{1}$ que dificulta sua utilização direta em programas de melhoramento. No entanto, deve-se ressaltar que existem outras possibilidades que podem ser utilizadas em conjunto para se identificar marcas mais próximas ao loco que controla o florescimento precoce na progênie estudada. Uma delas, já em desenvolvimento pelo grupo de pesquisa (Farro, 2001; Bortoloto, 2003), consiste na elaboração de um mapa genético saturado para a progênie em estudo, que poderia ser o ponto de partida para a clonagem de genes relacionados ao florescimento ("map-based cloning"). Outra estratégia, muito utilizada na avaliação de QTLs (Gratapaglia et al., 1996; Nietsche et al., 2000; Junghans et al., 2003) seria a elaboração de "bulks" mais direcionados, utilizando os fenótipos extremos da progênie para análise de BSA. Nesse caso, poderiam ser elaborados "pools" de DNA de árvores que floresceram em menor tempo e dos indivíduos que mais demoraram a apresentar flores, com o objetivo de se encontrar outros marcadores mais eficientes para o melhoramento assistido.

\section{"Bulked Segregant Analysis" (BSA) no melhoramento florestal}

Em algumas espécies vegetais, a BSA requer uma grande quantidade de "primers" RAPD, e de progênies F2 ou F3 para a avaliação de seus resultados. Yang et al. (2004) utilizaram 820 marcadores e progênies F1 e F2 para o mapeamento de um gene de resistência em milho; em cevada, foram necessários 186 "primers" e a análise de 140 linhagens para a identificação de genes de resistência por BSA (Kutcher et al., 1996). No entanto, o presente trabalho demonstra que a BSA tem grande utilidade em programas de melhoramento genético de espécies florestais, e em especial do eucalipto, pois, com um grupo inicial de 20 indivíduos (os "bulks") e algumas dezenas de "primers" RAPD, já puderam ser localizados marcadores relacionados ao florescimento precoce.

\section{CONCLUSÕES}

Os dados obtidos no presente trabalho permitem chegar às seguintes conclusões:

- A técnica de "Bulked Segregant Analysis" (BSA) é eficiente na identificação de marcadores de DNA de interesse para o melhoramento genético em eucalipto.

- Com essa técnica, foi possível identificar um marcador RAPD relacionado ao florescimento precoce em uma progênie de Eucalyptus grandis e desenvolver o primeiro marcador SCAR para a espécie.

\section{AGRADECIMENTOS}

Os autores deste trabalho agradecem à Suzano Bahia Sul Papel e Celulose SA, ao Prof. Dr. Ivan de Godoy Maia, à Tânia Mara Bortoloto, ao Darío Abel Palmieri e à Cristiane de Camargo Teixeira pela ajuda na condução das etapas de laboratório; e ao Dr. Marcos Aparecido Gimenes pelas sugestões e leitura crítica do manuscrito. Douglas Silva Domingues recebeu bolsa de Iniciação Científica da Fundação de Amparo à Pesquisa do Estado de São Paulo (FAPESP).

\section{REFERÊNCIAS BIBLIOGRÁFICAS}

ARAKI, T.; KOBAYASHI, Y.; KAYA, H.; GOTO, K.; IWABUCHI, M. A pair of related genes with antagonistic roles in mediating flowering signals. Science, v. 286, p.1960-1962, 1999.

AVILA, C.M.; SILLERO, J.C.; RUBIALES, D.; MORENO, M.T.; TORRES, A.M. Identification of RAPD markers linked to the Uvf-1 gene conferring hypersensitive resistance against rust (Uromyces viciae-fabae) in Vicia faba L. Theoretical and Applied Genetics, v. 107, p. 353-358, 2003. 
BORTOLOTO, T.M. Mapeamento de marcadores RAPD em uma população F1 de Eucalyptus grandis. Botucatu, 2003. 28f. Monografia (Bacharelado em Ciências Biológicas) - Instituto de Biociências, Universidade Estadual Paulista, Botucatu, 2003.

BRONDANI, R.P.V.; BRONDANI, C.; GRATTAPAGLIA, D. Toward a genus-wide reference linkage map for Eucalyptus based exclusively on highly informative microsatellite markers. Molecular Genetics and Genomics, v. 267, p. 338-347, 2002.

BRONDANI, R.P.V; BRONDANI, C.; TARCHINI, C., GRATTAPAGLIA, D. Development, characterization and mapping of microsatellite markers in Eucalyptus grandis and E. urophylla. Theoretical and Applied Genetics, v. 97, p. 816-827, 1998.

DORNELAS, M.C.; RODRIGUEZ, A.P.M.; AMARAL, W.A.N. Cloning of LEAFY homologues in tropical tree species. In: CONGRESSO NACIONAL DE GENÉTICA, 48., 2002, Águas de Lindóia. Resumos... São Paulo: SBG, 2002. 1 CD-ROM. p.334.

FARRO, A.P.C. Desenvolvimento de um mapa de microsatélites de Eucalyptus grandis. Botucatu, 2001. 55f. Dissertação (Mestrado em Ciências Biológicas) - Instituto de Biociências, Universidade Estadual Paulista, Botucatu, 2001.

FERREIRA, M.E., GRATTAPAGLIA, D. Introdução ao uso de marcadores moleculares em análise genética. Brasília: EMBRAPA-CENARGEN, 1998. 220p.

GRATTAPAGLIA, D.; BERTOLUCCI, F.L.; SEDEROFF, R.R. Genetic mapping of QTLs controlling vegetative propagation in Eucalyptus grandis and E. urophylla using a pseudo-testcross strategy and RAPD markers. Theoretical and Applied Genetics, v. 90, p. 933-947, 1995.

GRATTAPAGLIA, D.; BERTOLUCCI, F.L.G.; PENCHEL, R.; SEDEROFF, R.R. Genetic mapping of Quantitative Trait Loci controlling growth and wood quality traits in Eucalyptus grandis using a maternal half-sib family and RAPD markers. Genetics, v.144, p. 1205-1214, 1996.

GRATTAPAGLIA, D.; SEDEROFF, R.R. Genetic linkage maps of Eucalyptus grandis and Eucalyptus urophylla using a pseudo-testcross mapping strategy and RAPD markers. Genetics, v.137, p. 1121-1137, 1994.

JUNGHANS, D.T. Quantificação da severidade, herança da resistência e identificação de marcadores RAPD ligados à resistência à ferrugem (Puccinia psidii) em Eucalyptus grandis. Viçosa, 2000. 53f. Tese (Doutorado em Fitopatologia) - Universidade Federal de Viçosa, Viçosa, 2000.

JUNGHANS, D.T.; ALFENAS, A.C.; BROMMONSCHENKEL, S.H.; ODA, S.; MELLO, E.J.; GRATTAPAGLIA, D. Resistance to rust (Puccinia psidii Winter) in Eucalyptus: mode of inheritance and mapping of a major gene with RAPD markers. Theoretical and Applied Genetics, v. 108, p. 175-180, 2003.

KUTCHER, H.R.; BAILEY, K.L.; ROSSNAGEL, B.G.; LEGGE, W.G. Identification of RAPD markers for common root rot and spot blotch (Cochliobolus sativus) resistance in barley. Genome, v. 39, n. 1, p. 206-215, 1996.

KYOZUKA, J.; HARCOURT, R.; PEACOCK, W.J; DENNIS, E.S. Eucalyptus has functional equivalents of the Arabidopsis AP1 gene. Plant Molecular Biology, v. 35, p. 573-584, 1997.

LEITE, S.M.M.; BONINE, C.A.; MORI, E.S.; VALLE, C.F.; MARINO, C.L. Genetic Variabililty in a breeding population of Eucalyptus urophylla S.T. Blake. Silvae Genetica, v. 51, n. 5-6, p. 253-256, 2002.

LEVY, Y.Y.; DEAN, C. Control of flowering time. Current Opinion in Plant Biology, v. 1, p. 49-54, 1998.

LEVY, Y.Y.; DEAN, C. The transition to flowering. Plant Cell, v. 10, p. 1973-1989, 1998.

MARTINS FILHO, S.; SEDIYAMA, C.S.; MOREIRA, M.A.; BARROS, E.G. RAPD and SCAR markers linked to resistance to frogeye leaf spot in soybean. Genetics and Molecular Biology, v. 25, n. 3, p. 317-321, 2002.

MEZZENA, L. Monitoramento da variabilidade genética de populações de melhoramento de Eucalyptus grandis por marcadores RAPD e SSR. Botucatu, 2003. 68f. Dissertação (Mestrado em Ciências Biológicas: Genética) Instituto de Biociências, Universidade Estadual Paulista, Botucatu, 2003.

MICHELMORE, R.W.; PARAN, I.; KESSELI, R.V. Identification of markers linked to disease-resistance genes by bulked segregant analysis: a rapid method to detect markers in specific genomic regions by using segregating populations. Proceedings of the National Academy of Sciences USA, v. 88, p. 9828-9832, 1991.

MISSIAGGIA, A.A.; PIACEZZI, A.; GRATTAPAGLIA, D. A major effect QTL for early flowering in eucalyptus mapped by selective genotyping of microsatellite markers detected in fluorescent multiplexes. In: CONGRESSO NACIONAL DE GENÉTICA, 48., 2002, Águas de Lindóia. Resumos... São Paulo: SBG, 2002. 1 CD-ROM. p. 573. 
MORETZSOHN, M.C.; NUNES, C.D.M; FERREIRA, M.E.; GRATTAPAGLIA, D. RAPD linkage mapping of the shell thickness locus in oil palm (Elaeis guineensis Jacq.) Theoretical and Applied Genetics, v. 100, p. 63-70, 2000.

NIETSCHE, S.; BORÉM, A.; CARVALHO, G.A.; ROCHA, R.C.; PAULA JR., T.J.; BARROS, E.G.; MOREIRA, M.A. RAPD and SCAR markers linked to a gene conferring resistance to angular leaf spot in common bean. Journal of Phytopathology, v. 148, p. 117-121, 2000.

OR, E.; HOVAV, R.; ABBO, S. A major gene for flowering time in chickpea. Crop Science, v. 39, p. 315-322, 1999.

PARAN, I.; MICHELMORE, R.W. Development of reliable PCR based markers linked to downy mildew resistance gene in lettuce. Theoretical and Applied Genetics, v. 85, p. 985-993, 1993.

PENA, L.; MARTIN-TRILlO, M.; JUAREZ, J.; PINA, J.A.; NAVARRO, L.; MARTINEZ-ZAPATER J.M. Constitutive expression of Arabidopsis LEAFY or APETALA1 genes in citrus reduces their generation time. Nature Biotechnology, v. 19, n. 3, p. 215-216, 2001.

PREACHER, K. J. Calculation for the chi-square test: an interactive calculation tool for chi-square tests of goodness of fit and independence. 2001. Disponível em: <http://www.quantpsy.org/.> Acesso em: 20 jun. 2006.

RAMEAU, C., DÉNOUE, D., FRAVAL, F., HAUROGNÉ, K., JOSSERAND, J., LAUCOU, V., BATGE, S., MURFET, I.C. Genetic mapping in pea. 2. Identification of RAPD and SCAR markers linked to genes affecting plant architecture. Theoretical and Applied Genetics, v. 97, n. 5-6, p. 916-928, 1998.

ROCHA, R.B., MURO-ABAD, J.I., ARAÚJO, E.F, CRUZ, C.D. Avaliação do método centróide para estudo de adaptabilidade ao ambiente de clones de Eucalyptus grandis. Ciência Florestal, v. 15, n. 3, p. 255-266, 2005.

SOUTHERTON, S.G.; STRAUSS, S.H.; OLIVE, M.R.; HARCOURT, R.L.; DECROOCQ, V.; ZHU, X.; LLEWELLYN, D.J.; PEACOCK, W.J.; DENNIS, E.S. Eucalyptus has a functional equivalent of Arabidopsis floral meristem identity gene $L E A F Y$. Plant Molecular Biology, v. 37, p. 897-910, 1998.

TAR'AN, B.; WARKENTIN, T.; SOMERS, D.J.; MIRANDA, D.; VANDENBERG, A.; BLADE, S.; WOODS, S.; BING, D.; XUE, A.; DeKOEYER, D.; PENNER, G. Quantitative trait loci for lodging resistance, plant height, and partial resistance to mycosphaerella blight in field pea (Pisum sativum L.). Theoretical and Applied Genetics, v. 107, n. 8, p. 1482-1491, 2003.

THAMARUS, K.A.; GROOM, K.; MURRELL, J.; BYRNE, M.; MORAN, G.F. A genetic linkage map for Eucalyptus globulus with candidate loci for wood, fibre and floral traits. Theoretical and Applied Genetics, v. 104, p. 379-387, 2002.

VERHAEGEN, D.; PLOMION, C. Genetic mapping in Eucalyptus urophylla and Eucalyptus grandis using RAPD markers. Genome, v. 39, p. 1051-1061, 1996.

WIRTHENSOHN, M.G., COLLINS, G., JONES, G.P., SEDGLEY, M. Variability in waxiness of Eucalyptus gunni foliage for floriculture. Scientia Horticulturae, v. 82, p. 279-288, 1999.

WEIGEL, D.; ALVAREZ, J.; SMYTH, D.R.; YANOFSKY, M.F.; MEYEROWITZ, E.M. LEAFY controls floral meristem identity in Arabidopsis. Cell, v. 69, p. 843-859, 1992.

YANG, D.E.; ZHANG, C.L.; ZHANG, D.S.; JIN, D.M.; WENG, M.L.; CHEN, S.J.; NGUYEN, H.; WANG, B. Genetic analysis and molecular mapping of maize (Zea mays L.) stalk rot resistant gene Rfg1. Theoretical and Applied Genetics, v. 108, p. 706-711, 2004.

YANOFSKY, M.F.; MA, H.; BOWMAN, J.L.; DREWS, G.N.; FELDMAN, K.A.; MEYEROWITZ, E.M.: The protein encoded by the Arabidopsis homeotic gene agamous resembles transcription factors. Natur, v. 346, p. 35-39, 1990. 